\title{
Hospital admission rates for asthma and respiratory disease in the West Midlands: their relationship to air pollution levels
}

\author{
S Walters, M Phupinyokul, J Ayres
}

\begin{abstract}
Background-A study was undertaken to determine the relationship between hospital admissions for asthma and all respiratory conditions in electoral wards in the West Midlands and ambient levels of smoke, sulphur dioxide, and nitrogen dioxide, and to establish whether the relationship is independent of social deprivation and ethnicity, and is different for young children and older individuals.

Methods - Data on hospital admissions for acute respiratory conditions were obtained by electoral ward from the West Midlands Regional Health Authority Information Department Körner inpatient data including asthma (ICD 493) and all acute respiratory disease $(466,480-486,490-496)$ for the period April 1988 to March 1990. The population for each electoral ward, percentage of ward population that was from non-white ethnic groups, and Townsend deprivation score were all calculated from 1991 census information. Data on smoke and sulphur dioxide $\left(\mathrm{SO}_{2}\right)$ levels were obtained for 24 wards in Birmingham, Coventry, Wolverhampton, Dudley, Stafford, and Burton-on-Trent, and on nitrogen dioxide $\left(\mathrm{NO}_{2}\right)$ levels from 39 wards in the same local authority areas. All were background urban sites and most participated in the Warren Spring national quality control programme for $\mathrm{SO}_{2}$ and smoke monitoring. Indirect age-sex stand-

were not associated with hospital admissions. Multivariate analysis including Townsend score and percentage of nonwhite subjects in the model revealed that $\mathrm{NO}_{2}$ was associated with hospital admission rates for all respiratory conditions only for children under 5 . The Townsend score was associated with SHR for all respiratory conditions, and both the Townsend score and percentage of non-white subjects were associated with SHR for asthma in children under 5 in two of three models. The association between SHR for asthma and percentage of non-white subjects was negative.

Conclusions - Socioeconomic deprivation, as measured by the Townsend score, is a significant predictor of hospital admission rates for respiratory disease in older individuals, and both the percentage of nonwhite subjects and the Townsend score are significant predictors of hospital admission rates for asthma in children. After correction for socioeconomic deprivation and ethnicity, background urban $\mathrm{NO}_{2}$ levels in the ward of residence are significantly associated with standardised hospital admission rates for all respiratory disease in children under 5 . This may represent a causal effect of $\mathrm{NO}_{2}$ on the respiratory health of children, or the effect of confounding factors not corrected by use of the Townsend score.

(Thorax 1995;50:948-954)
\end{abstract} ardised hospitalisation rates (SHR) for all respiratory conditions and asthma were calculated using the 1991 rates for the West Midlands RHA as the standard. Multivariate regression models were used to assess the relationship between individual pollutants and the SHR. The Townsend score and percentage of the population from non-white ethnic groups were included in all models to adjust for ethnicity and socioeconomic deprivation.

Results - The SHR for asthma varied almost fourfold across the region, and all respiratory SHR showed more than three fold variation. Bivariate regression revealed both Townsend score and percentage of non-white individuals to be associated with SHR for asthma and all respiratory conditions at all ages, but not for children under 5 years. $\mathrm{NO}_{2}$ was associated with hospital admission rates for all ages including children under $5 . \mathrm{SO}_{2}$ and smoke
Keywords: asthma, hospital admissions, pollution, children.

Interest in the health effects of air pollution has increased in recent years in the United Kingdom. This interest concerns both the acute health effects of air pollution in causing reduced lung function or exacerbation of existing respiratory conditions, and the long term effects of air pollution in causing a higher prevalence of respiratory illness among people living in polluted areas.

Hospital admissions among children for asthma and other respiratory conditions have been rising in the West Midlands, with higher rates occurring in urban areas. ${ }^{1}$ This trend has been observed in other parts of the United Kingdom ${ }^{2}$ and abroad. ${ }^{3}$ Although studies vary in the definition of asthma employed, prevalence of asthma in children has been estimated at up to $12 \%,{ }^{4}$ with up to $25 \%$ reporting 
a history of wheeze. ${ }^{5}$ In adults the cumulative prevalence of wheeze has been estimated as up to $7 \% .^{6}$ In the West Midlands over $1 \%$ of all boys and $0.5 \%$ of all girls under 5 are admitted to hospital each year with an asthma attack. ${ }^{1}$ The high prevalence of, and rising hospital admission rates for, asthma raise the question as to whether this might be related to air pollution levels.

Previous studies in the United Kingdom have suggested that the prevalence of respiratory symptoms might be related to ambient air pollution levels. In a series of cross sectional studies in Sheffield schoolchildren the prevalence of respiratory tract symptoms was associated with the ambient levels of sulphur dioxide $\left(\mathrm{SO}_{2}\right)$ and smoke in the area of residence. ${ }^{7}$ This effect was no longer apparent five years later when the levels of particulates had fallen markedly. ${ }^{8}$ The UK National Study of Health and Growth showed the prevalence of respiratory symptoms to be associated with ambient smoke pollution levels in the area of residence, ${ }^{9}$ but an associated longitudinal study showed no change in prevalence of respiratory symptoms with falls in air pollution over time.$^{10}$ Other studies noticed differences between urban and rural environments in prevalence of respiratory symptoms in children of manual workers. ${ }^{11} \mathrm{~A}$ difficulty with many cross sectional studies has been the low power because of relatively few participating areas, and difficulty in controlling for other potential causative factors such as cigarette smoking.

Another important series of studies has been the Six Cities Study from the USA. The first study showed that the prevalence of cough in children was associated with measures of particulates, $\mathrm{SO}_{2}$, and sulphate, but there was no association within the cities and no effect on lung function. ${ }^{12} \mathrm{~A}$ subsequent study which measured fractionated particulates confirmed the findings of the original study: cough, bronchitis, and chest illness were all associated with all measures of particulates, but not hay fever, wheezing, or asthma. Again, no effects were seen on lung function in the children, and there were indications that acid aerosols might be important determinants of symptoms. ${ }^{13}$ Studies on the prevalence of respiratory symptoms in children have confirmed that, in cross sectional studies, respiratory symptoms, but not lung function, tend to be associated with levels of $\mathrm{SO}_{2}$, particulates, or both. ${ }^{14-16}$ One study in Canada has suggested that very low levels of outdoor $\mathrm{SO}_{2}, \mathrm{NO}_{2}$, and sulphate may be associated with small but significant reductions in lung function in children. ${ }^{17}$

It is more difficult to determine the effects of air pollution on the prevalence of respiratory disease in adults due to the potential confounding effects of socioeconomic status, smoking, and occupational exposure. A series of studies in non-smoking Seventh Day Adventists in California examined the prevalence of respiratory symptoms in groups with different pollution exposures. Although particulates, $\mathrm{SO}_{2}, \mathrm{NO}_{2}$, oxidants, nitrates, and sulphates were measured, only total suspended particulates (TSP) showed a significant association with the prevalence of respiratory symptoms at relatively high levels of exposure $(200 \mu \mathrm{g} /$ $\left.\mathrm{m}^{3}\right) \cdot{ }^{1819}$ Lung function in lifetime non-smoking young adults was also associated with ambient particulate levels in the US National Health and Nutrition Survey, although no other pollutants were measured.$^{20}$ Hospital admission rates in Utah were significantly associated with levels of $\mathrm{PM}_{10}$ (particulates with a diameter below $10 \mu \mathrm{m})$, and fell markedly when the steel mill which was the source of most $\mathrm{PM}_{10}$ was closed for a period of time. ${ }^{21}$ Outdoor $\mathrm{NO}_{2}$ was found to be significantly associated with the duration of recorded respiratory symptoms in children in Switzerland, although the incidence of respiratory episodes was associated with particulate levels. $^{22}$ In another Swiss study, outdoor $\mathrm{NO}_{2}$ levels were associated with prevalence of recorded respiratory symptoms in preschool children, even after adjustment for tobacco smoke exposure and indoor $\mathrm{NO}_{2}$ levels. ${ }^{23}$ Both particulates and $\mathrm{NO}_{2}$ levels were found to be associated with post-neonatal respiratory mortality in the Czech republic in a recent study. ${ }^{24}$

Published evidence suggests that air pollution, and particularly ambient levels of particulates and possibly nitrogen dioxide, are associated with the prevalence of respiratory symptoms, although the evidence that these pollutants affect lung function is less conclusive, as is the evidence that reductions in pollution levels result in a fall in the prevalence of respiratory disease. Nevertheless, there is good evidence that acute health effects related to air pollution levels can occur, and experimental evidence that $\mathrm{SO}_{2},{ }^{25}$ oxides of nitrogen, ${ }^{26}$ and ozone ${ }^{27}$ can act as bronchoconstrictors or lower the threshold to other constrictor agents ${ }^{28}$ in asthmatic subjects. It is therefore reasonable to suggest that hospital admission rates for respiratory diseases and asthma may differ between areas with different levels of air pollution. Although levels of particulate pollution and $\mathrm{SO}_{2}$ have been falling since the $1950 \mathrm{~s}$, both nationally ${ }^{29}$ and locally (Appleby $\mathbf{R}$, personal communication), the sources of composition of urban air pollution have changed, with increasing proportions coming from motor vehicle emissions and with rising levels of emissions of hydrocarbons and oxides of nitrogen. ${ }^{28}$

There have been no recent studies in the UK relating hospital admission rates for respiratory diseases to ambient pollution levels, particularly at current low levels of particulates and $\mathrm{SO}_{2}$, and relatively high levels of $\mathrm{NO}_{2}$. Nor have there been any studies of small administrative areas. This study was undertaken to see whether local variations in ambient air pollution levels in urban areas of the West Midlands were associated with differences in hospital admission rates, and whether these differences were independent of socioeconomic deprivation, ethnicity, and other potential confounding factors.

\section{Methods}

\section{DATA SOURCES}

Data on hospital admissions for residents of 
Birmingham, Dudley, Wolverhampton, Coventry, Stafford, and Burton were obtained by electoral ward from the West Midlands Regional Health Authority Information Department for the two year period April 1988 to March 1990. This covered hospital admissions for asthma (ICD-9 code 493) and all acute respiratory conditions (ICD-9 codes 466 , $480-486$ and 490-496). Population data, including the percentage of the population from non-white ethnic groups, were obtained for all electoral wards. Townsend ${ }^{30}$ scores for each electoral ward, also based on the 1991 census, were calculated and supplied by the West Midlands Regional Health Authority Information Department. The use of Townsend scores as a method of adjusting for socioeconomic deprivation is discussed fully below.

Air pollution data were obtained by request from the Environmental Health Departments of local authorities in the West Midlands. Birmingham and Coventry city councils, Wolverhampton and Dudley metropolitan district councils, and Stafford and Burton district councils all supplied information. Data on smoke and $\mathrm{SO}_{2}$ were provided for 24 sites in total, of which 18 were included in national quality control networks or had an equivalent degree of quality control applied. All measurements of $\mathrm{SO}_{2}$ were made by the hydrogen peroxide absorption method, ${ }^{31}$ and particulates were measured by the British black smoke method. ${ }^{31}$ All sites were background urban sites - that is, they were not close to a kerbside or major industrial source - and were therefore designed to reflect exposures for the general population. All sites were maintained as part of routine monitoring networks and none was specifically established for this study. The British black smoke method is likely to underestimate total particulate load, particularly in cities, because coloured particulates may constitute a variable minority of total particulates. ${ }^{32}$ In urban areas a high proportion of measured smoke comes from diesel exhaust emissions. ${ }^{33}$ It is recognised that this study may have underestimated particulate load to a variable extent between localities, depending on local

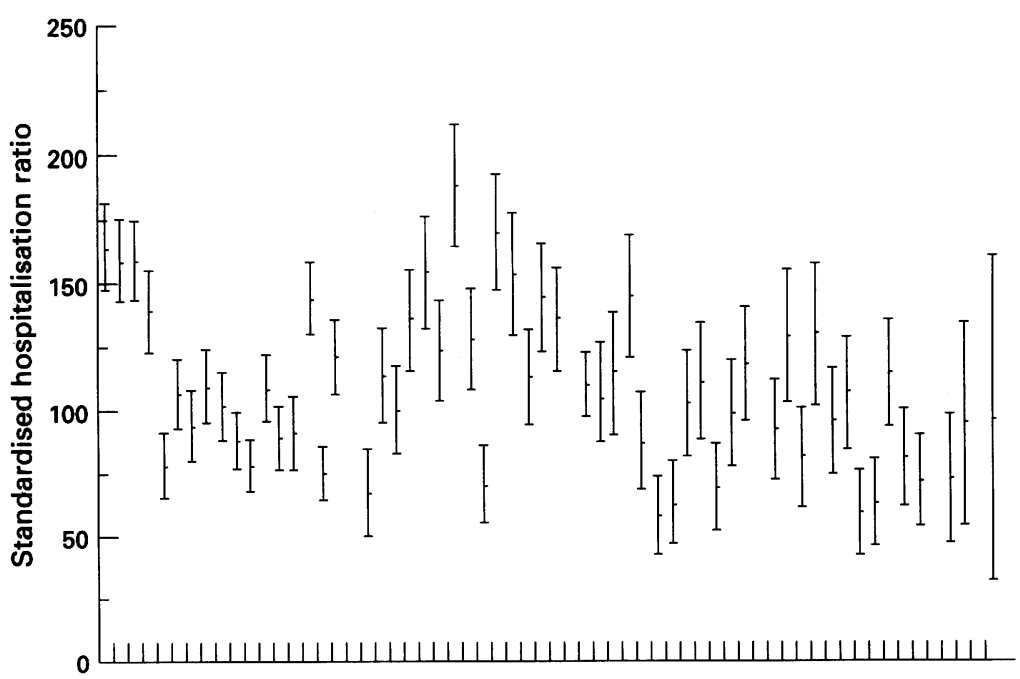

Figure 1 Standard hospitalisation ratios (with confidence intervals) for all respiratory conditions for electoral wards in the study. sources of black smoke, but the monitoring method used was the only one available at the time of the study. Nitrogen dioxide was measured using diffusion tubes. ${ }^{34}$ All of these were placed at urban background sites to measure four week average nitrogen dioxide levels. Data were available for a total of 39 such sites. The quality control of these measurements was less standardised than for $\mathrm{SO}_{2}$ and smoke measurements, and most of the measurements and quality control were performed by local council departments. Only six wards contained monitoring stations for all three pollutants. Interpolation of results for electoral wards which did not contain a monitoring station was not possible in the absence of emissions inventories, because many wards contain industrial point sources or major roads, and because of the relatively large distances between the monitoring stations. This was likely to produce gross levels of error in the interpolated estimates in the absence of confirmatory information, and the study was felt to be sufficiently powerful without this additional source of error.

\section{DATA ANALYSIS}

Age-sex standardised hospitalisation ratios (SHRs) were calculated by the indirect method for all electoral wards in the study. The reference rates used in the calculation were hospital admission rates for asthma and all respiratory conditions for the West Midlands Regional Health Authority in 1991. This was used because of the relative accuracy of the 1991 census population information compared with intercensal estimates for 1989 or 1990 . $95 \%$ confidence intervals were calculated using the formula:

\section{SHR $\pm 1.96 \sqrt{ }$ (observed/expected $\times 100$}

Use of the large sample approximation was justified because total observed admissions for asthma and all respiratory disease were large (between 20 and 500).

Two year mean levels of smoke, $\mathrm{SO}_{2}$, and $\mathrm{NO}_{2}$ were calculated for each electoral ward in the study - that is, each ward which contained a monitoring station. The relationship between SHR and mean levels of pollutants was then investigated by bivariate and multivariate regression. Bivariate regression was carried out to determine the relationship between these pollutants, hospital admissions, ethnicity, and Townsend scores. This was performed for children under 5 and for people of all ages. Children under 5 were studied separately because they consitute the group in whom hospital admission rates for asthma are highest, and in whom the rates are rising most quickly. They also represent a group more likely to stay within a short distance of their home address during the day, and therefore are less affected by different exposure as a result of commuting long distances to work or school. It was not possible to separate out other age groups because of the small numbers of admissions in these groups.

Multiple least squares regression models were then constructed for Townsend score and 


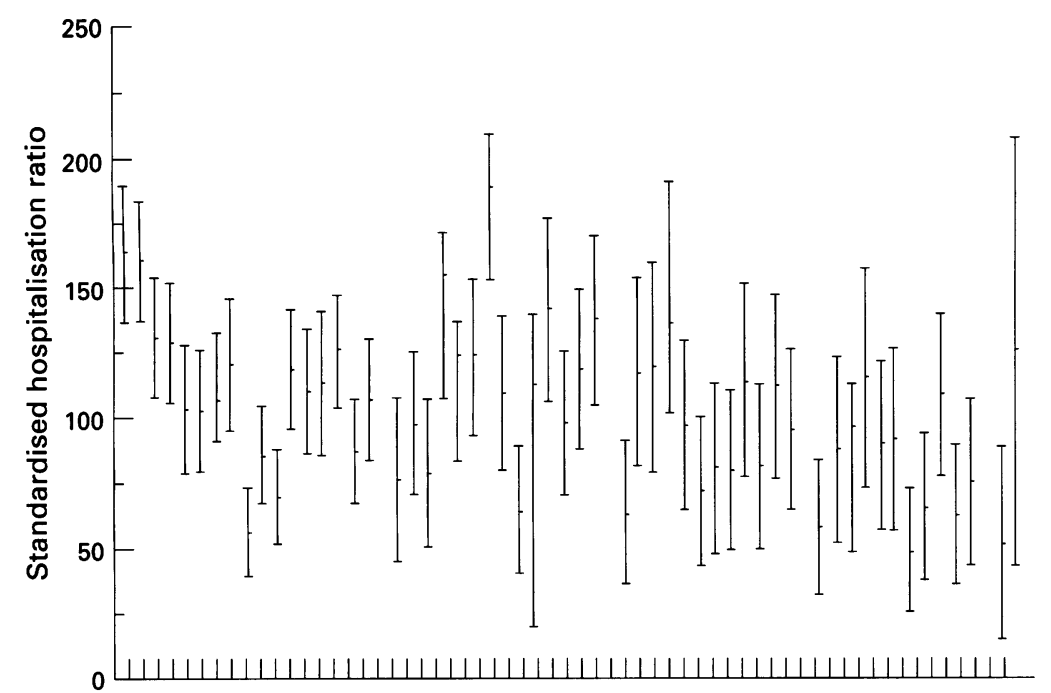

Figure 2 Standard hospitalisation ratios (with confidence intervals) for asthma for electoral wards in the study.

Table 1 Results of bivariate regression analysis between standardised hospitalisation rate (SHR) for asthma and respiratory diseases, ambient pollution levels, percentage nonwhite subjects, and Townsend scores

\begin{tabular}{|c|c|c|c|c|}
\hline \multirow[t]{2}{*}{ Independent variable } & \multicolumn{2}{|l|}{ All ages } & \multicolumn{2}{|c|}{ Children $<5$ years } \\
\hline & All respiratory & Asthma & All respiratory & Asthma \\
\hline $\begin{array}{l}\text { Townsend } \\
\text { x coefficient } \\
\text { p value } \\
R^{2}\end{array}$ & $\begin{array}{c}5 \cdot 78 \\
<0.0001 \\
0.55\end{array}$ & $\begin{array}{c}4.20 \\
<0.0001 \\
0.33\end{array}$ & $\begin{array}{c}\mathrm{NS}_{0.05}^{2.25} \\
0.05\end{array}$ & $\begin{array}{c}1.66 \\
\mathrm{NS} \\
0.04\end{array}$ \\
\hline $\begin{array}{l}\text { Smoke } \\
\text { x coefficient } \\
\text { p value } \\
R^{2}\end{array}$ & $\begin{array}{l}0.83 \\
\text { NS } \\
0.01\end{array}$ & $\begin{array}{l}0 \cdot 18 \\
\text { NS } \\
0 \cdot 001\end{array}$ & $\begin{array}{c}2.49 \\
\text { NS } \\
0.05\end{array}$ & $\begin{array}{l}0.17 \\
\mathrm{NS} \\
0.0004\end{array}$ \\
\hline $\begin{array}{l}\text { Sulphur dioxide } \\
\text { x coefficient } \\
\text { p value } \\
R^{2}\end{array}$ & $\begin{array}{l}-0.68 \\
\text { NS } \\
0.03\end{array}$ & $\begin{array}{l}\stackrel{0.073}{\text { NS }} \\
0.0005\end{array}$ & $\begin{array}{l}-1 \cdot 63 \\
\text { NS } \\
0.07\end{array}$ & $\begin{array}{l}0 \cdot 117 \\
\text { NS } \\
0.0005\end{array}$ \\
\hline $\begin{array}{l}\text { Nitrogen dioxide } \\
\text { x coefficient } \\
\text { p value } \\
R^{2}\end{array}$ & $\begin{array}{c}2.61 \\
<0.001 \\
0.28\end{array}$ & $\begin{array}{l}2.38 \\
<0.001 \\
0.26\end{array}$ & $\begin{array}{c}2 \cdot 36 \\
<0 \cdot 005 \\
0 \cdot 20\end{array}$ & $\begin{array}{r}1.63 \\
<0.05 \\
0.12\end{array}$ \\
\hline $\begin{array}{l}\text { Percentage non-white } \\
\text { x coefficient } \\
\text { p value } \\
R^{2}\end{array}$ & $\begin{array}{l}0.89 \\
<0.0005 \\
0.22\end{array}$ & $\begin{array}{c}0.84 \\
<0.005 \\
0.22\end{array}$ & $\begin{array}{l}0.09 \\
\text { NS } \\
0.001\end{array}$ & $\begin{array}{l}0.03 \\
\text { NS } \\
0.002\end{array}$ \\
\hline
\end{tabular}

each pollutant in turn. Ethnicity was added to these models to allow for any additional independent effect. Partial $\mathrm{x}$ coefficients, $\mathrm{p}$ values and summary $R^{2}$ values were calculated.

\section{Results}

STANDARDISED HOSPITALISATION RATIOS (SHR)

The SHR values for asthma and respiratory disease, together with confidence limits, are presented for electoral wards in the study in figs 1 and 2 .

RELATIONSHIP BETWEEN HOSPITAL ADMISSIONS AND AIR POLLUTION

Results of bivariate regression analysis between SHR, each pollutant, ethnicity, and Townsend score are given in table 1 . There were significant relationships between both the Townsend score and ethnicity and hospital admissions at all ages for asthma and all respiratory conditions, but not for children under 5 . Levels of $\mathrm{NO}_{2}$ in the ward of residence were significantly associated with hospital admissions for asthma and all respiratory diseases at all ages, and specifically for children under 5 .

The results of multivariate analysis between SHR, Townsend score, and percentage of nonwhite subjects with each pollutant included in turn in the model are given in table 2 . These results show that at all ages the Townsend score, but none of the pollutants, is a significant predictor of hospital admission rates for all respiratory conditions. The Townsend score is also a significant predictor of hospital admission rates for asthma when $\mathrm{NO}_{2}$, but not other pollutants, are included in the model. For children under 5 the Townsend score is not a significant determinant of hospital admission rates for all respiratory conditions. However, in this group both the Townsend score and the percentage of non-white subjects were significant independent predictors of hospital admission rates for asthma in models which included smoke or $\mathrm{SO}_{2}$, but not in models which included $\mathrm{NO}_{2} . \mathrm{NO}_{2}$ is significantly associated with SHR for respiratory admissions in children under 5, and this association is independent of the Townsend score and the percentage of non-white subjects. $\mathrm{NO}_{2}$ is not significantly associated with SHR for asthma. No other pollutants showed significant association with SHR for asthma or all respiratory conditions after adjusting for the Townsend score and ethnicity.

Over the range of measured levels of $\mathrm{NO}_{2}$, a $30 \mu \mathrm{g} / \mathrm{m}^{3}$ increase in the two year mean $\mathrm{NO}_{2}$ level in an electoral ward might be expected to increase SHR for all respiratory conditions by $63 \%$.

A scatter plot showing the significant relationship between $\mathrm{NO}_{2}$ and SHR for respiratory disease in children under 5 is shown in fig 3 .

Table 2 Results of multivariate analysis between standardised hospitalisation rate (SHR) for asthma and respiratory disease, ambient pollution levels, ethnicity and Townsend scores

\begin{tabular}{|c|c|c|c|c|c|c|c|c|c|c|c|c|}
\hline & \multicolumn{6}{|l|}{ All ages } & \multicolumn{6}{|c|}{ Children under 5 years } \\
\hline & \multicolumn{3}{|c|}{ All respiratory } & \multicolumn{3}{|l|}{ Asthma } & \multicolumn{3}{|c|}{ All respiratory } & \multicolumn{3}{|l|}{ Asthma } \\
\hline & Pollutant & Townsend & $\%$ non-white & Pollutant & Townsend & $\%$ non-white & Pollutant & Townsend & $\%$ non-white & Pollutant & Townsend & $\%$ non-white \\
\hline $\begin{array}{l}\text { Smoke } \\
\text { x coefficient } \\
\text { p values } \\
\mathrm{SO}_{2}\end{array}$ & $\mathrm{NS}^{0.58}$ & $\begin{array}{l}5.68 \\
0.0001\end{array}$ & $\begin{array}{l}-0 \cdot 58 \\
\text { NS }\end{array}$ & $\mathrm{NS}^{0 \cdot 15}$ & $\begin{array}{l}2 \cdot 00 \\
\mathrm{NS}\end{array}$ & $\begin{array}{l}0 \cdot 3 \\
\text { NS }\end{array}$ & $\stackrel{2 \cdot 02}{\mathrm{NS}}$ & $\mathrm{NS}^{5 \cdot 19}$ & $\begin{array}{l}-1 \cdot 09 \\
\mathrm{NS}\end{array}$ & $\begin{array}{l}-0.32 \\
\text { NS }\end{array}$ & $\begin{array}{r}5.98 \\
<0.01\end{array}$ & $\begin{array}{l}-1.49 \\
<0.01\end{array}$ \\
\hline $\begin{array}{l}\mathrm{x} \text { coefficient } \\
\mathrm{p} \text { values } \\
\mathrm{NO}_{2}\end{array}$ & $\begin{array}{l}-0 \cdot 64 \\
\text { NS }\end{array}$ & $\begin{array}{l}5 \cdot 51 \\
0.0001\end{array}$ & $\mathrm{NS}^{0.006}$ & $\begin{array}{l}-0.99 \\
\text { NS }\end{array}$ & $\mathrm{NS}$ & $\begin{array}{l}0.32 \\
\text { NS }\end{array}$ & $\begin{array}{l}4 \cdot 99 \\
\mathrm{NS}\end{array}$ & $\overline{N S}^{-1 \cdot 18}$ & ${ }_{\mathrm{NS}}^{-1 \cdot 00}$ & $\mathrm{NS}^{1 \cdot 17}$ & $\begin{array}{c}6.59 \\
<0.005\end{array}$ & $\begin{array}{l}-1 \cdot 7 \\
<0.005\end{array}$ \\
\hline $\begin{array}{l}\mathrm{x} \text { coefficient } \\
\mathrm{p} \text { values }\end{array}$ & $\mathrm{NS}^{0.9}$ & $\begin{array}{l}5 \cdot 65 \\
0.0001\end{array}$ & $\begin{array}{l}-0 \cdot 11 \\
\text { NS }\end{array}$ & $\mathrm{NS}^{1 \cdot 01}$ & $\begin{array}{r}3.11 \\
<0.05\end{array}$ & $\begin{array}{l}0.34 \\
\text { NS }\end{array}$ & $\begin{array}{c}2 \cdot 2 \\
<0 \cdot 05\end{array}$ & $\mathrm{NS}^{1 \cdot 7}$ & $\begin{array}{l}-0.37 \\
\text { NS }\end{array}$ & $\mathrm{NS}^{1 \cdot 35}$ & $\mathrm{NS}^{1 \cdot 18}$ & $\begin{array}{l}-0 \cdot 1 \\
\text { NS }\end{array}$ \\
\hline
\end{tabular}




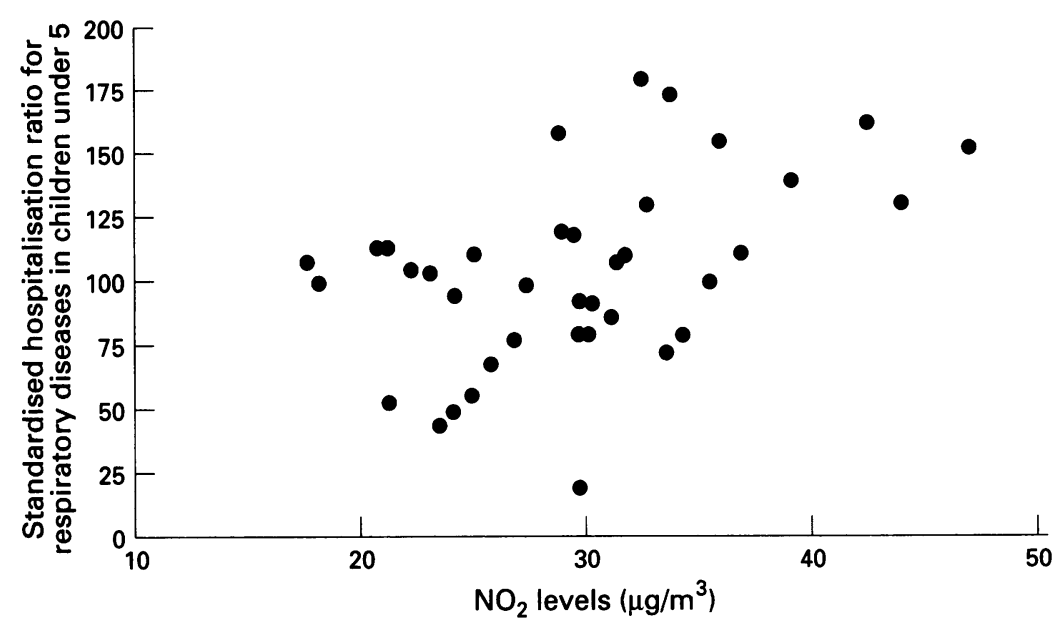

Figure 3 Scatter plot of standardised hospitalisation ratio for respiratory diseases in children under five years versus two year ambient $\mathrm{NO}_{2}$ levels in 39 electoral wards in the West Midlands, 1988-90. recent review for the West Midlands Regional Health Authority the Townsend score was found to be very closely associated with SHRs by electoral ward for all hospital conditions, ${ }^{38}$ to reflect more closely hospital admission rates than other indices of deprivation, ${ }^{1}$ to show negative associations with hospital admission rates in those conditions in which it would be expected - for example, breast cancer, ${ }^{1}$ and to be closely associated with SHRs for respiratory conditions. ${ }^{39}$

There are some potential drawbacks to the use of the Townsend score. The use of electoral wards as administrative areas on which the Townsend score is calculated means that an electoral ward with an extremely poor estate at one end and affluent areas at the other would give a Townsend score which does not adequately reflect the level of deprivation of people in some parts of the ward. It can also be argued that it does not adequately reflect deprivation in rural areas because of its inclusion of car ownership - poor people in rural areas without a car may be much more deprived than in urban areas with plentiful public transport. In the context of this study this is less relevant, since all wards were urban or suburban. Nevertheless, we believe the use of the Townsend score is the best practicable method of correction for socioeconomic deprivation available in the West Midlands at present.

We also know that socioeconomic deprivation is closely associated with other potential confounding factors for the prevalence of respiratory disease, such as poor housing quality, ${ }^{4041}$ cigarette smoking (active and passive), ${ }^{42-44}$ and other environmental determinants of health. Although we might expect cigarette smoking prevalence to increase with increased socioeconomic deprivation and thus be associated with the Townsend score, this may not provide adequate correction for smoking prevalence or other potential confounding factors such as occupational exposure.

For children the Townsend score is a relatively poor predictor of SHR for all respiratory conditions, but it is a strong positive predictor of SHR for asthma. The proportion of the population from non-white ethnic groups was also a strong independent negative predictor of SHR for asthma in two of our three models. This suggests that SHR for asthma tends to be highest in deprived electoral wards with a low proportion of the population from non-white ethnic groups. A negative association between ethnicity and hospital admissions for asthma may reflect lower prevalence of asthma, reduced severity of asthma, or reduced use of or access to hospital services.

This study could not take into account the possibility that hospital admission rates are different in different non-white ethnic groups because of the small numbers from different ethnic groups resident in some electoral wards, which meant a composite index had to be used.

There may also be difficulties in assuming that the ambient levels of pollutants in an electoral ward are a reflection of exposure of the population of that ward. People frequently commute long distances and may spend much eral practitioners in an urban area. The latter attempts to measure directly material deprivation, and includes four variables relating to employment, car ownership, owneroccupation, and overcrowding. The Townsend score has been shown to be closely associated with mortality in a number of studies. ${ }^{3037}$ In a 
of their lives exposed to very different concentrations of pollutant. In addition, indoor air may be contaminated with a variety of pollutants, particularly $\mathrm{NO}_{2}$, which has been shown at least in some studies to be associated with a prevalence of respiratory symptoms. ${ }^{45}$ Preschool children tend to remain closer to home, and the fact that significant associations between the SHR and outdoor $\mathrm{NO}_{2}$ measurements were found in this study only in this group suggests that population movements may be an important source of error for exposure estimation in an ecological study of this kind. Levels of $\mathrm{NO}_{2}$ may also vary within electoral wards with respect to local sources such as major roads, resulting in uneven exposure across the ward.

The admission of patients to hospital, even for emergency conditions, is a complex process involving a series of factors other than just the clinical status of the patient and severity of symptoms. It is a chain of social and behavioural decisions which may be influenced by many factors. Social circumstances may lead patients from one part of the West Midlands to seek help in an emergency from a hospital whilst others might turn to primary care services, and this will affect subsequent hospital admission rates. The availability of services, distance from the hospital, availability of transport, and hospital admissions policies may also play an important part in hospital admissions, although all wards in this study were in urban areas with good transport links and relatively close to acute hospitals. Hospital admissions represent the extreme end of the spectrum of respiratory morbidity that may be due to environmental factors, but the division between hospital admission, use of primary care services, and self treatment is not influenced by clinical status alone, and therefore hospital admission rates, even when adjusted for socioeconomic deprivation, may not reflect the true pattern of respiratory morbidity within an electoral ward.

Finally, some of the differences in recorded hospital admission rates may be due to differences in hospital information and diagnostic coding systems, particularly for wards whose patients attend different hospitals. This has been minimised by including all respiratory diagnoses as well as asthma in the analysis, but there may still be differences in the proportions of admissions with no recorded diagnosis. Likewise, differences in recorded pollution levels may be due to slight methodological differences between local authorities in siting of stations and data collection. These differences have been minimised as far as possible by selecting sites employing high levels of quality control, including those in a national air pollution monitoring network, but some differences may still exist. If systematic differences between administrative areas exist for both hospital information systems and air pollution measurements, this introduces the possibility of bias.

This study has found an independent association between $\mathrm{NO}_{2}$ levels and hospital admission rates for all respiratory diseases in children under 5 . These findings are consistent with those fom Switzerland ${ }^{23}$ where outdoor $\mathrm{NO}_{2}$ levels were associated with prevalence of respiratory symptoms, and a study from Japan where changing prevalence of respiratory symptoms in atopic children was associated with $\mathrm{NO}_{2}$ levels. ${ }^{46}$ A study from Germany also showed an association between $\mathrm{NO}_{2}$ and reported cases of croup. $^{47}$ However, most studies of prevalence of respiratory symptoms have shown associations with levels of particulates ${ }^{1213}$ and not $\mathrm{NO}_{2}$. The absence of a positive finding in this study may be due to the methodological difficulties mentioned above, or to the very low levels of particulates in the area studied, representing a threshold effect. The acute effects of $\mathrm{NO}_{2}$ on respiratory function have produced equivocal results in the literature. Some studies have shown effects of $\mathrm{NO}_{2}$ on lung function ${ }^{489}$ and on bronchial reactivity, ${ }^{5051}$ whilst others have not. ${ }^{5253}$ There is some suggestion that the young may be more susceptible than older subjects, ${ }^{54}$ which would be consistent with our findings. It is possible that $\mathrm{NO}_{2}$ affects hospital admissions for acute respiratory exacerbations through its reported effects on susceptibility to respiratory viral infection, ${ }^{55}$ although this association is not proven in humans. This might explain the significant association with SHR for all respiratory conditions, which includes infections, but not asthma. The findings of this study with respect to hospital admission rates for respiratory illness in children and $\mathrm{NO}_{2}$ levels are thus biologically plausible and consistent with other studies.

This study has shown that socioeconomic status as measured by the Townsend score is an important predictor of hospital admission rates for acute respiratory disease, that ethnicity is an important independent predictor of hospital admission rates for asthma in children under 5 , and that in children under 5 the SHR for respiratory diseases is significantly associated with ambient outdoor $\mathrm{NO}_{2}$ levels after adjustment for both socioeconomic status and ethnicity. It is therefore possible that ambient $\mathrm{NO}_{2}$ levels could affect either prevalence or severity of asthma in children. However, because of the methodological difficulties associated with the use of routinely collected data in an ecological study of this kind, further confirmatory studies of the potential health effects of air pollution in the UK are required. These should include assessment of potential confounding factors for respiratory disease, such as smoking, occupation and housing quality, as well as assessment of indoor pollution exposure and personal pollution exposure. Further research is needed to determine the potential effects of $\mathrm{NO}_{2}$ and other pollutants on the respiratory health of individuals, and particularly young children.

The authors would like to thank the West Midlands Regional Health Authority Information Department, and the Environmental Services Departments of Birmingham and Coventry city councils, Wolverhampton and Dudley metropolitan district councils, and Stafford and Burton district councils, without whom this study would not have been possible.

1 West Midlands Regional Health Authority. Partners in Health: Annual Report of the Regional Director of Public Health 1992. West Midlands RHA: 1992. 
2 Anderson HR. Increase in hospital admissions for childhood asthma: trends in referral, severity and readmissions from asthma: trends in referral, severity and readmissions from 1970 to 1985 in a healt

3 Evans R, Mullally DI, Wilson RW, Gergen PJ, Rosenberg HM, Grauman JS, et al. National trends in morbidity and mortality of asthma in the US - prevalence, hospitalisation and death from asthma over two decades 1965-1984. Chest 1987;91:614-9.

4 Burr ML, Butland MK, King S, Vaughan-Williams E. Changes in asthma prevalence: two surveys 15 years apart. Arch Dis Child 1989;64:1452-6.

5 Leeder SR, Corkhill R, Irwig LM, Holland WW, Colley JRT. Influence of family factors on incidence of lower respiratory tract illness during the first year of life. $\mathrm{Br} \%$ Prev Soc Med 1976;30:203-12.

6 Gellert AR, Gellert SL, Iliffe DR. Prevalence and management of asthma in a London inner-city general practice. Br F Gen Pract 1990;40:197-201.

7 Lunn JE, Knowelden J, Handyside AJ. Patterns of respiratory illness in Sheffield infant school children. $\mathrm{Br} f$ Prev Soc Med 1967;21:7-16.

8 Lunn JE, Knowelden J, Roe JW. Patterns of respiratory illness in Sheffield junior school children. $B r\}$ Prev Soc Med 1970;24:223-8.

9 Melia RJ, Florey CD, Swan AV. Respiratory illness in British schoolchildren and atmospheric smoke and sulphur dioxide 1973-7: I Cross-sectional findings. f Epidemiol Com munity Health 1981;35:161-7.

10 Melia RJ, Florey CD, Chinn S. Respiratory illness in British schoolchildren and atmospheric smoke and sulphur dioxide 1973-7: II Longitudinal findings. F Epidemiol Com munity Health 1981;35:168-73.

11 Colley JR, Douglas JW, Reid DD. Respiratory disease in young adults: influence of early respiratory tract illness, social class, air pollution and smoking. $B M F$ 1973;3: 195.

12 Ware JH, Ferris BG, Dokery DW, Spengler JD, Stram DO, Speizer FE. Effects of ambient sulfur oxides and suspended particulates on respiratory health of preadolescent children. Am Rev Respir Dis 1986;133:834-42.

13 Dockery DW, Speizer FE, Stram DO, Ware JH, Spengle JD, Ferris BG. Effects of inhalable particles on respiratory
health of children. Am Rev Respir Dis 1989;139:587-94.

14 Dodge R, Solomon P, Moyers J, Hayes C. A longitudina study of children exposed to sulfur oxides. $A m \mathfrak{F}$ Epidemio 1985;121:720-36.

15 Kagamimori S, Katoh T, Naruse Y, Watanabe M, Kasuya M, Shinkai J, et al. The changing prevalence of respiratory
symptoms in atopic children in response to air pollution. symptoms in atopic children in

16 Schenker MB, Vedal S, Batterman S, Samet J, Speize FE. Health effects of air pollution due to coal combustion in the Chestnut Ridge region of Pennsylvania: a crosssection survey of children. Arch Environ Health 1986 41:104-8.

17 Stern B, Jones L, Raizenne M, Burnett R, Meranger FC, Franklin CA. Respiratory health effects associated with ambient sulfates and ozone in two rural Canadian communities. Environ Res 1989;49:20-39.

18 Euler GL, Abbey DE, Magie AR, Hodgkin JE. Chronic obstructive pulmonary disease symptom effects of longterm cumulative exposure to ambient levels of total suspended particulates and sulfur dioxide in California Seventh-Day Adventist residents. Arch Environ Health 1988; 43:279-85.

19 Euler GL, Abbey DE, Hodgkin JE, Magie AR. Chronic obstructive pulmonary disease symptom effects of longterm cumulative exposure to ambient levels of total oxterm curn tive exposure to ambient levels of total oxidants and nitrogen dioxide in California Seventh-Day
Adventist residents. Anch Environ Health 1988;43:279-85.

20 Chestnut LG, Schwartz J, Savitz DA, Burchfiel CM. Pulmonary function and ambient particulate matter: Epimonary function and ambient particulate matter: EpiHealth 1991;46:1060-3.

21 Pope CA. Respiratory hospital admissions associated with PM10 pollution in Utah, Salt Lake and Cache Valleys. Arch Environ Health 1991;46:90-7.

22 Braun-Fahrlander C, Ackermann-Liebrich U, Schwartz J Gnehm H-P, Rutishauser M, Wanner H-U. Air pollution and respiratory symptoms in pre-school children. Am Rev Respir Dis 1992;145:42-7.

23 Rutishauser M, Ackermann U, Braun C, Gnehm H-P Wanner H-U. Significant association between outdoo $\mathrm{NO}_{2}$ and respiratory symptoms in pre-school children. $\mathrm{NO}_{2}$ and respiratory symptoms
Lung 1990;168(Suppl):347-52.

24 Bobak M, Leon DA. Air pollution and infant mortality in the Czech Republic 1986-88. Lancet 1992;340:1010-4.

25 Linn WS, Venet TG, Shamoo DA, et al. Respiratory effects of sulphur dioxide in heavily exercising asthmatics: a doseresponse study. Am Rev Respir Dis 1983;127:235-7.

26 Orehek J, Massoni JP, Gattard C, Charpin J. Effects of shortterm low level nitrogen dioxide exposure on bronchial 301-7.
27 Linn WS, Avol EL, Shamoo DA, Speir CE, Valencia LM, Venet TG, et al. Dose response study of healthy heavily exercising men exposed to ozone at concentrations near the ambient air quality standard. Toxicol Ind Health 1986; 2:99-112.

28 Molfino NA, Wright SC, Katz I, Tarlo S, Silerman F, McClean PA, et al. Effect of low concentrations of ozone on inhaled allergen responses in asthmatic subjects. Lancet 1991;338:199-203.

29 Quality of Urban Air Review Group. Urban air quality in the United Kingdom. London: Department of the Environment, 1993.

30 Townsend P, Phillimore P, Beattie A. Health and deprivation: inequality and the North. London: Routledge, 1989.

31 Harrison RM, Important air pollutants and their chemical analysis. In: Harrison RM, ed. Pollution: causes, effects and control. Cambridge: Royal Society of Chemistry, 1990.

32 Clarke AG, Willison MJ, Ziki EM. A comparison of urban and rural aerosol composition using a dichotomous sampler. Atmos Environ 1984;23:1767-1775.

33 Ball DJ, Caswell. Smoke from diesel engined road vehicles - an investigation into the basis of British and European emission standards. Atmos Envimn 1983;17:169-81.

34 Palmes ED, Gunnison AP, Dunattio J, Tomezyk C. Personal sampler for nitrogen dioxide. Am Ind Hyg Assoc $\mathcal{F} 1976$; 37:570-7.

35 Black D, Morris JN, Smith C, Townsend P. Inequalities in Health (The Black Report). London: Penguin Books, 1982

36 Jarman B. Identification of underprivileged areas. $B M \mathfrak{F}$ 1983;286:1705-9.

37 Campbell DA, Radford JMC, Burton P. Unemployment rates, an alternative to the Jarman index? BMF 1991;303: 750-5.

38 Institute of Public and Environmental Health. Deprivation and the West Midlands RHA Resource Allocation Formula. Birmingham: Institute of Public and Environmental Health, 1992 .

39 West Midlands Regional Health Authority. Action for Health: Annual report of the Regional Director of Public Health 1993. Birmingham: West Midlands RHA, 1993.

40 McCarthy P, Byrne D, Harrison S, Keithley J. Respiratory conditions: effect of housing and other factors. $\mathcal{F}$ Epidemiol Community Health 1985;39:15-9.

41 Platt SD, Martin CJ, Hunt SM, Lewis CW. Damp housing mould growth and symptomatic health state. $B M \mathcal{F} 1989$; 298:1673-8.

42 Leeder SR, Corkill R, Irwig LM, Holland WW. Influence of family factors on incidence of lower respiratory illness during the first year of life. $B r F$ Prev Soc Med 1976;30 203-12.

43 Fergusson DM, Horwood LJ, Shannon FT. Parental smoking and respiratory illness in infancy. Arch Dis Child 1980; 55:358-61.

44 Hasselblad V, Humble CG, Graham MG, Anderson HS Indoor environmental determinants of lung function in children. Am Rev Respir Dis 1981;123:479-85.

45 Neas LM, Dockery DW, Ware JH, Spengler JD, Speizer FE, Ferris BG Jr. Association of indoor nitrogen dioxide $\mathrm{FE}$, Ferris BG Jr. Association of indoor nitrogen dioxide with respiratory symptoms and pulmonary
children. Am $₹$ Epidemiol 1991;134:204-19.

46 Kagamimori S, Katoh T, Naruse Y, Watanabe M, Kasuya $\mathrm{M}$, Shinkai J, et al. The changing prevalence of respiratory symptoms in atopic children in response to air pollution. Clin Allergy 1986;16:299-308.

47 Schwartz J, Spix C, Wichmann HE, Malin E. Air pollution and acute respiratory illness in five German communities. Envinn Res 1991;56:1-14.

48 Avol EL, Linn WS, Peng RC, Whynot JD, Shamoo DA, Little DE, et al. Experimental exposures of young asthmatic volunteers to $0.3 \mathrm{ppm}$ nitrogen dioxide and to ammatic volunteers to $0 \cdot 3 \mathrm{ppm}$ nitrogen dioxide and to am

49 Koenig JO, Pierson WE, Covert DS, Marshall SG, Morgan MS, van Belle $G$. The effects of ozone and nitrogen dioxide on lung function in health and asthmatic adolescents. Res Rep Health Eff Inst 1988;14:5-24.

50 Mohsenin V. Airway responses to nitro matic subjects. $\mathcal{F}$ Toxicol Environ Health 1987;22:371-80.

51 Frampton MW, Morrow PE, Cox C, Gibb FR, Speers DM, Utell MJ. Effects of nitrogen dioxide exposure on pulmonary function and airway reactivity

52 Avol EL. Am Rev Respir Dis 1991;143:522-7. D, Hackney JD. Laboratory study of asthmatic volunteers exposed to nitrogen dioxide and to ambient air pollution. $A m$ Ind nitrogen dioxide and to amb
Hyg Assoc $\mathcal{F} 1988 ; 49: 143-9$.

53 Rubinstein I, Bigby BG, Reiss TF, Boushey HA Jr. Shortterm exposure to $0.3 \mathrm{ppm}$ nitrogen dioxide does not potentiate airway responsiveness to sulfur dioxide in asthmatic subjects. Am Rev Respir Dis 1990;141:381-5.

54 Drechsler-Parks DM, Bedi JF, Horvath SM. Pulmonary function responses of young and older adults to mixtures $\mathrm{O}_{3}, \mathrm{NO}_{2}$ and PAN. Toxicol Ind Health 1989;5:505-17.

55 Kulle TJ, Clements ML. Susceptibility to virus infection with exposure to nitrogen dioxide. Res Rep Health Eff Inst 1988;15:5-21. 